\title{
Photogenic Substance in the Firefly
}

\author{
Experiments Made to Ascertain How the Insect Produces Light \\ By E. Newton Harvey
}

P'revious research on the subject of biophotogenesis lias shown that at least three factors are necessary for the production of light, namely, water, oxvgen, and a photogenir substance. A fourth factor is probably also involved, an oxidizing enzyme, as in other organic oxidainvolved, an oxidizing enzyme, as in other organic oxidations. Concerning this enzyme nothing is known, at
least nothing definite in the case of the firefly. Indeed least nothing definite in the case of the firefly. Indeed,
Kastle's observations indicate that in the firefly no direct Kastle's observations indicate that in the firefly no direct oxidizing enzyme (oxvgenase) but small amounts of an indirect oxidizing enzyme (peroxidase) and a catalas are present.

The old observation that many luminous tissues can he dried and ground up and will phosphoresce, when water containing oxygen is again added, gives us a simple (hemical method of investigating the nature of the photo('hemical method of investigating the nature of the photo-
genic material. The dried material may be extracted genic material. The dried material may be extracted
with water-fres solvents (since the photogen does not with water-free solvents (since the photogen does not oxidize in absence of water), and extracted material as well as the residue from evaporation of the filtrate tested for phosphorescence by adding water. Or the dried material may be extracted with oxygen-free aqueous solvents (since the photogen does not oxidize with light production in absence of oxygen), and filtrate and residue tested as before by admitting oxygen. The first due tested as before by admitting oxygen. The first
method is satisfactory, and has indicated that a larg method is satisfactory, and has indicated that a large
number of fat solvents will extract nothing from the number of fat solvents will extract nothing from the drird lissue and yet leave the photogenic material unhoiling ether for twenty-four hours without impairing 1ts power to phosphoresce. Boiling alcohol does destroy the power to phosphoresce, and the nature of its action is discussed below. These results, as well as the previous results of McDermott. (Journ. $4 \mathrm{~m}$. ('hem. Soc. 1911, results of McDermott (Journ. 4m. Chem. Soc., 1911,
xxxiii., 1791: Smithsonian Report, 1911, 345) and Dubois xxxiii., 1791: Smithsonian Report, 1911, 345) and Dubot
(Orig. Comm. Sth Intern. C'ongr. Appl. Chem., 1912, xix. (()rig. Comm. Sth Intern. Congr. Appl. Chem., 1912, xix.
8(6), using fresh watery material, show that the photorenic substance is not a fat or fat-like body of any kinc.

The second method-that of extraction with oxygen-fre water solutions-is not satisfactory because the photorenic substance breaks up, or at least loses its power 1.0 phosphoresce, on standing in contact with water for any longth of time even if no oxygen is present. Many aicompts were made to extract the dried material with l'mpts were made to extract the dried material with aqueous solvents, and filter the extract in absence of
oxygen before it was recognized that such attempts were futile because of the instabiity of the photogenic sulstance in oxygen-free water.

My experiments were begun in the winter of 1913 on firetly material collected at Princeton, N. J., and dried over $\mathrm{CaCl}_{2}$ in a vacuum. (See preliminary note, Harvey, Science, 1914, xl., 33.) I am greatly indebted also to $\mathrm{Mr}$. F. Alex. MeDermolt, of the Mellon Institute, University F. Alex. MeDermott, of the Mellon Institute, University
of Pittsburgh, for an additional supply of material with which the work was continued. Mr. MeDermott ha been making experiments along similar lines with a some what different apparatus, and his results are likewise published in the Journal of the Amerrcan Chemical Societ (loc. cil.) As luminous material may be found which does not disintegrate in water the apparatus used for oxygenfree extraction is described below.

The material to be extracted is placed in the vessel $C$ (in the drawing), provided with a ground-in stopper connected with a 120-degree stopcock. The water to be rendered free of oxygen is placed in $B$ after passing hydrogen through stopeock $C$, and closing it. $B$ is connected through $A$ with a hydrogen generator. The hydroge is passed through potassium hydroxide to remove acid, and then over a glowing platinum wire (in $A$ ) to remove the last traces of oxygen, a much better method than the last traces of oxygen, a much better method than nately exhausting $B$ through $b$, connected to an air-pump nately exhausting $B$ through $b$, connected to an air-pump,
and refilling with hydrogen several times the water can be quickly rendered free of oxygen. $C$ is then connected to $B$ throsgh $c$, and one of the arms of the 120-degre stopeock $(d)$ whose other arm is connected with an airpump. $\quad C$ and the arms of $d$ are then exhausted. The 120-degree stopeock is then turned to connect $C$ and $B$ and $c$ is openerl, allowing the pressure of the hydrogen 1. drive the solvent on the material in $C$. The proper amount of fluid for extraction should be placed in $B$ so that the hydrogen may follow it through and fill the that the hydrogen may follow it through and fill the
('hamber $C$. Then $d$ is closed, when $C$ can be disconnected and shaken during extraction. To filter the extract it is only necessary to connert one of the arms of d with a desiceator fitted with funnel and filter rack When the desicrator is exhausted, $C$ and the desiceator are connected, and the pressure of the hydrogen in drives the extract onto the filter-paper. The firefly photogen begins to phosphoresce when the atmospheri pressure reaches 5 to 6 millimeters, which means an oxygen pressure of 1 to 1.2 millimeters. Consequently, it is necessary to use a good vacuum pump and make connections air-tight. I found small bore lead tubing conn If If one extracts with distilled water for a short time
(fifteen minutes) and then filters, on admitting oxygen the filtrate is found to be dark while the residue on the filter-paper shows the bright points of light characteristic of the power of the firefly. But if the extraction be carried out for an hour or more, neither the filtrate nor the residue will phosphoresce when oxygen is admitted. All of my experiments have been carried out in the dark, and the material observed at eritical stages (as when the oxygen-free water was added) to make sure that no light appeared, and always with negative results. But to make sure that no very slow leakage of oxygen into th filtering chamber occurred, I have carried out the extraction in a special tube provided with a capillary sealed off during the extraction. After extracting in this tube for one and one half hours and admitting oxygen no phosphorescence appeared. Thinking that possibly the pho-

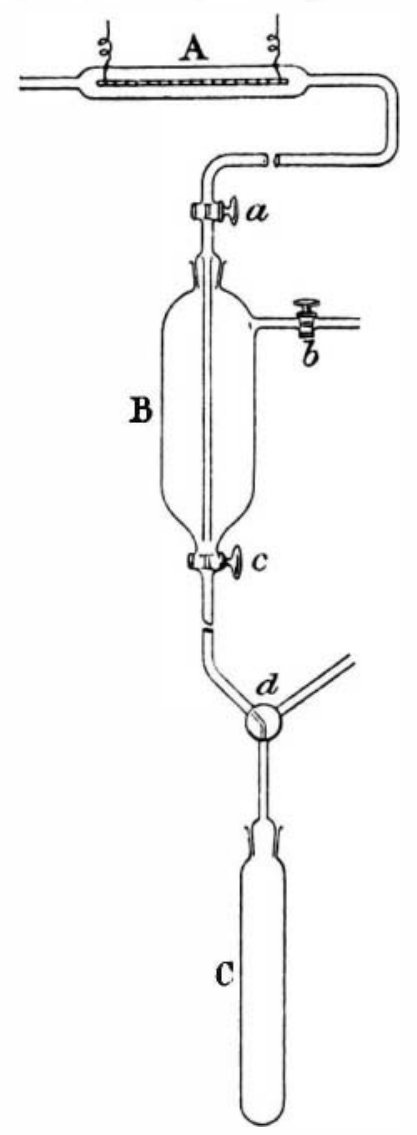

togen dissolved in the extracting fluid did phosphoresce but only so faintly as to be invisible because distributed through a relatively large volume of extract fluid, the unfiltered extract was evaporated in vacuo to a small volume. This can be very easily done by placing the rubber tube from the vacuum pump over the capillary onto the special tube, exhausting, and then breaking the eapillary through the walls of the rubber tube to connect with the air-pump. Even when concentrated the extract gave no light on adding oxygen.

The photogen is therefore destroyed in distilled water without oxidation. The search for a watery solvent for photogen becomes then a search for a solvent in which the photogen is stahle. The following solution were tried in addition to distilled water. Fxtraction was allowed to proceed for from 1 to 1.5 hours.

1. Ringer's solution (as representing fairly accurately the concentration and composition of the firefly's blood)

2. $0.125 \mathrm{M} \mathrm{NaCl}$

3. Sea-water (a mixture of chlorides and sulphates of $\mathrm{Na}, \mathrm{K}, \mathrm{Ca}$, and $\mathrm{Mg}$ ).

4. Five per cent $\mathrm{NaCl}$.

5. $0.05 \mathrm{M} \mathrm{NaOH}$ and $0.01 \mathrm{M} \mathrm{NaOH}$. The dried powdered firefly organs will phosphoresce strongly if sprinkled on the surface of $0.1 \mathrm{M} \mathrm{NaOH}$.

6. $0.02 \mathrm{M} \mathrm{HCl}$. Dried firefly powder will phosphoresce on $0.0125 \mathrm{M} \mathrm{HCl}$ and on $0.025 \mathrm{M} \mathrm{HCl}$, but less brilliantly. Only one or two hright dots appear on 0.05 M HCl, anc nophosphoresceence ocedurs on (). I M IIC. If nentralized within two minutes after contact with the acid the light does not appear in the $0.1 \mathrm{M} \mathrm{HCl}$ treated material nor become brighter in the $0.05 \mathrm{M}$ and $0.025 \mathrm{M}$ material. In each caso after extraction, oxygen was admitted and the solution shaken, yet in no ease did light appear either in the undissolver residue or in the solution. The $0.02 \mathrm{M} \mathrm{HCl}$ extract was also neutralized as it is well known that the acid prevents biophotogenesis. The conditions of phosphorescence in the firefly are therefore more complex than at first supposed. Either the photogen, the enzymes, the enzyme activators, or all three, uvdergo changes which are not oxidative in nature, when the material stands in contact with water for a time sufficient to dissolve out the luminous material. Both McDermott's results and mine agree perfectly, and while negative and disappointing they are deemed worthy of publication as indicating that water, oxygen, and a photogenic substance are not the only factors involved in light production, and also as showing the instability of the photogen.

My work with water-free solvents has been confined to those listed in Table 1, which gives also the time of extraction, temperature, and results. TABLE I.

\begin{tabular}{|c|c|c|c|c|}
\hline Sulsstance. & ڤّ & 薯 & 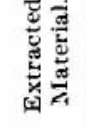 & 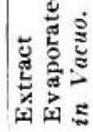 \\
\hline Sther $(\operatorname{cold} 1) \ldots \ldots \ldots \ldots \ldots$ & 20 & 72 & + & \\
\hline Ether (hot)........ & 55 & 24 & + & \\
\hline ('hloroform (cold) ................. & 20 & 72 & + & \\
\hline Chloroform (hot)............ & 61 & 8 & + & \\
\hline Ethyl alcohul (cold). & 20 & 24 & + & \\
\hline Ethyl alcohol (hot) .................. & 784 & 24 & - & \\
\hline Ethyl alcohol and ether (equal parts) & & & & \\
\hline hoiling ...................... & 44 & 10) & + & - \\
\hline ('arbon tetrachloride. . . . . . . . . . & 20 & 48 & + & \\
\hline (arbon disulphide. ................ & 20 & 48 & - & \\
\hline Acetone...................... & 20 & 48 & + & \\
\hline T'oluol ........ & 20 & 48 & + & \\
\hline A miyl alcohol & 20 & th & very & \\
\hline Ethyl butyrate... & 20 & 18 & $\begin{array}{c}\text { raint* } \\
\text { Very } \\
\text { faint* }\end{array}$ & _ \\
\hline
\end{tabular}

* The material was washed with echer to remove the amyl alcohol and cthyl butyrate.

$\Lambda$ plus sign indicates phosphorescence when water is added, and a minus sign indicates no phosphorescence. Both the original extracted material and the residue of the filtered extract evaporated to dryness were examined. The results indicate that the photogenic substance is not a fat or oil, and also not a lecithin. J am aware that the lecithins are difficult to extract in toto from the cell, but this can be accomplished by a mixtnre of hot ether and alcohol, and yet a mixture of hot ether and alcohol will extract nothing which will phosphoresce from the firefly powder. We may safely say that the photngen is not a lecithin.

Of all the solvents tried only hot alcohol and cold amyl alcohol and ethyl butyrate gave results that would indieate a possible solution of the photogenic substance. And yet there is nothing in the filtrate residue that will phosphoresce when water or a neutralized 3 per cent solution of $\mathrm{H}_{2} \mathrm{O}_{2}$ is added. Thinking that oxidizing enzymes might be necessary, and that these had not been extracted by the fat solvents although the photogen had, the filtrate was also tested by adding a water extract of firefly organs, fresh or preserved with toluol or ehloroform, and also by potato-juice which contains considerable quantities of oxidizing enzymes. In no case was phosphorescence observed. The boiling ethyl alcohol (see Note), cold amyl alcohol, and ethyl butyrate must therefore break up the photogen. It is the alcohol itself and not the temperature (78.4 degrees) of boiling alcohol which is responsible for the destruction of the photogen, as the dried powder will withstand this temperature for twentyfour hours without any appreciable diminution in its power to phosphoresce. McDermott finds that liquid sulphur dioxide and liquid ammonia also destroy the photogenic power.

(Note.-The 99.8 per cent absolute alcohol was distilled over metallic calcium and collected in a receiver protected from the air by $\mathrm{CaCl}_{2}$ in order to remove the last traces of water.)

The powder obtained by drying cultures of luminous hacteria behaves similarly to the firefly material.

These results indicate that it will be a vastly more difficult problem to isolate and identify the photogenic. substances than might at first be supposed. -Journal of the American C'hemical Society. 